\title{
Conceptual knowledge of oral health among school teachers in South India, India
}

\author{
P. Jagan ${ }^{1}$, Nusrath Fareed ${ }^{2}$, Hemanth Battur ${ }^{2}$, Sanjeev Khanagar ${ }^{2}$, Manohar Bhat ${ }^{3}$
}

Correspondence: Dr. P. Jagan

Email: jaganbds1987@gmail.com

\begin{abstract}
'Department of Public Health Dentistry, Sri Ramakrishna Dental College and Hospital, Coimbatore, Tamilnadu, India,

2Department of Public Health Dentistry, KVG Dental College and Hospital, Sullia (D.K.), Karnataka, India, ${ }^{3}$ Department of Dentistry, Mysore Medical College, Mysore, Karnataka, India
\end{abstract}

\section{ABSTRACT}

Objective: To measure conceptual oral health knowledge among school teachers using comprehensive measure of oral health knowledge $(\mathrm{CMOHK})$ instrument. Materials and Methods: A total of 240 school teachers drawn through cluster random sampling from across Sullia taluk. Conceptual knowledge was assessed using Comprehensive measure of oral health knowledge questionnaire. Oral health status was recorded on a World Health Organization oral health assessment Proforma. Results: Overall distribution of CMOHK scores revealed that 106(44\%) subjects had good conceptual oral health knowledge, $81(33.7 \%)$ subjects had fair and 53(22\%) subjects were categorized under poor conceptual knowledge respectively. Statistically significant difference was observed for mean scores for conceptual knowledge in relation to gender $(12.8 \mathrm{v} / \mathrm{s} 15.3)$, in terms of type of school teachers (14.4 v/s 11.2) and in relation to age of the subjects. Primary school teachers exhibited a consistently better CMOHK scores 0.003(0.001-0.011) compared to their high school counterparts 0.003(0.001-0.012). Conclusion: The mean CMOHK score of this group was $12.5 \pm 1.3$ and is considered to be fair. There is an inverse association between age, educational levels and income in relation to CMOHK scores.

Key words: Oral health knowledge, oral health literacy, oral health status, school teachers

\section{INTRODUCTION}

The concept of health literacy initially emerged in the 1970s and continues to gain strength as an approach to improve health status. ${ }^{[1]}$ It essentially means placing one's own health and that of one's family and community into the context of understanding the factors that are influencing it and knowing how to address them..$^{[1]}$ Theoretical understandings and methods of evaluating health literacy have been in continual evolution ever since the idea of health literacy was first put forward in the 1970s. ${ }^{[2]}$ Research clearly links low levels of education, literacy, and

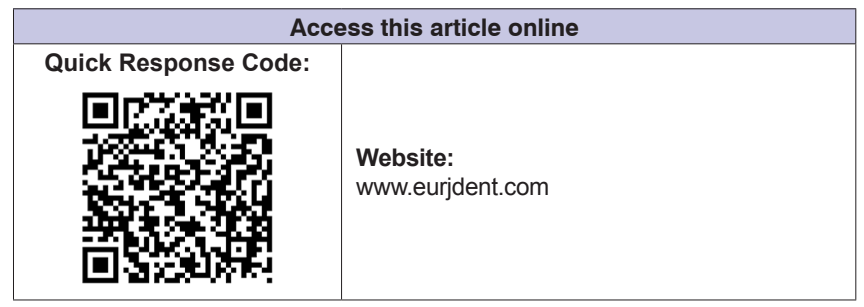

health literacy with poor health, poor health care utilization, increased barriers to care, and premature mortality around the world. ${ }^{[2]}$

Lower levels of health literacy are associated with poorer health, lesser understanding of prevention, maintenance, and self-care instructions.$^{[3]}$ These are the skills that are particularly critical in the management of chronic diseases including the oral diseases. ${ }^{[3]}$ Oral health literacy is defined as the "degree to which individuals have the capacity to obtain, process, and

This is an open access article distributed under the terms of the Creative Commons Attribution-NonCommercial-ShareAlike 3.0 License, which allows others to remix, tweak, and build upon the work non-commercially, as long as the author is credited and the new creations are licensed under the identical terms.

For reprints contact: reprints@medknow.com

How to cite this article: Jagan $\mathrm{P}$, Fareed N, Battur H, Khanagar S, Bhat M. Conceptual knowledge of oral health among school teachers in South India, India. Eur J Dent 2018;12:43-8.

DOI: 10.4103/ejd.ejd_93_17 
understand basic oral health information and services needed to make appropriate health decisions." [4] Limited literacy skills among adults are widespread and are hypothesized to have a large effect on oral health disparities, creating a barrier to achieve better oral health outcomes. Management of oral disease requires detailed understanding of complex self-care regimens as well as strict adherence to recall intervals; aspects of care which are related to oral health literacy ${ }^{[3]}$

Assessment of oral health literacy skills is generally carried out by the instruments such as the Rapid Estimate of Adult Literacy in Dentistry-30 (REALD-30), REALD-99, and the Test of Functional Health Literacy in Dentistry. These instruments are divided into two types: word recognition tests and comprehension tests. Word recognition tests are those in which participants read aloud a list of common medical words, test the ability to recognize, or read and pronounce individual words. Comprehension tests, on the other hand, assess a person's ability to understand written texts. ${ }^{[5]}$ None of the developed instruments stress on the individuals decision-making skills.

More recently, research has shown that difficulties with reading and word recognition probably do not influence health outcomes directly. It is difficult to imagine how word recognition influences an individual's unmet oral health needs, which needs numerous health-related decisions to be made by that individual, along the way. ${ }^{[6]}$ Macek et al. have identified several intervening factors between health literacy and oral health outcomes. Word recognition and reading comprehension alone probably do not fully explain the role that health literacy plays, rather conceptual knowledge is hypothesized to have a more direct relationship to oral health outcomes than either word recognition or reading comprehension. Conceptual knowledge is a key component of health literacy that has received little attention. ${ }^{[6]}$

Macek et al. have recently developed a conceptual oral health knowledge instrument which analyzes the findings in the context of a conceptual framework that lists word recognition, reading comprehension, conceptual knowledge, and communication skills as independent, yet related health literacy components and more importantly links health literacy with oral health decision-making and outcomes. ${ }^{[6]}$

With this background, this study was undertaken to assess the levels of conceptual knowledge of oral health among school teachers in Sullia Taluk, Dakshina Kannada district, in South India. The present study also had an additional objective to assess the oral health status of school teachers through world health organization oral health assessment pro forma (2013). ${ }^{[6]}$

\section{MATERIALS AND METHODS}

A cross-sectional descriptive epidemiological study was conducted among school teachers employed in the schools of Sullia Taluk, Dakshina Kannada, South India. Ethical clearance was obtained from the institutional review board, and the permission to conduct the study was obtained from the concerned authorities. Sample size was estimated with the power of $80 \%$ and $95 \%$ confidence interval for a prevalence of $50 \%$. Thus, the sample size obtained was 240. A sample proportionate to size was drawn from 35 schools randomly selected schools. Stratified cluster sampling methodology was employed for the selection of samples. Sullia Taluk has a total of 93 schools, of which 79 schools were from rural area and 14 schools were from urban area. Sixty-five schools were managed by the government, whereas 14 schools were under private management. A total of 35 schools were selected by means of simple random selection and included in the study.

\section{Inclusion criteria}

All willing participants with informed consent drawn from the included schools of Sullia Taluk, Dakshina Kannada, were included.

\section{Exclusion criteria}

Teachers who were edentulous, undergoing orthodontic treatment and those having a history of pregnancy were excluded.

The study was conducted over a period of 3 months (August-October) 2015. The data were collected by an investigator himself on a specially designed pro forma containing three parts.

- Part A - It recorded the basic demography of the participants

- Part B - It was a self-administered, pretested, structured questionnaire containing statements on conceptual oral health knowledge ${ }^{[6]}$

- Part C - It recorded oral health status according to the recommendations given by the WHO. ${ }^{[7]}$

ADA-specified Type III examination was followed to record the clinical parameters by investigator himself. 
The questionnaire was pilot tested for its feasibility and validity. A few modifications were done and the pro forma was finalized. Test-retest reliability was performed to test the reliability of the questionnaire; it was found to be good with Cronbach's alpha $(\alpha) 0.75$. Intra-examiner reproducibility determined using the kappa statistic was 0.85 .

\section{Statistical analysis}

Statistical analysis was performed through IBM SPSS Statistics for Windows, Version 21.0. Armonk, NY: IBM Corp. Descriptive data were recorded; Chi-square and ANOVA tests were conducted to test significance of the findings. Conceptual knowledge was assessed as per the recommendations given by the author. Regression analysis was further performed to find out the odds for each significant finding. $P$ value was set $\leq 0.05$

\section{RESULTS}

Analysis of the sociodemographic characteristics of the studied population revealed that approximately almost equal number of participants were present in different age groups and from different geographical areas as well as different types of schools. A significantly higher proportion of teachers were from the public schools teaching predominantly the vernacular language (91\%).

Analysis of the educational qualification of the participants revealed a minimum qualification of diploma in education as held by $45 \%$, whereas $55 \%$ among them were graduates.

There were differences in income of the participants included in the study as socioeconomic status of the family was considered. Scores from 0 to 11 represented "poor," from 12 to 14 corresponded to "fair," and from 15 to 23 represented "good" conceptual oral health knowledge. Overall distribution of Comprehensive Measure of Oral Health Knowledge (CMOHK) scores revealed that $106(44 \%)$ participants had good, 81 (33.7\%) participants had fair, and $53(22 \%)$ participants were categorized under poor conceptual knowledge. Statistically, significant difference was observed for mean scores for conceptual knowledge in relation to gender (12.8 vs. 15.3), in terms of type of school teachers (14.4 vs. 11.2), and in relation to age of the participants as shown in Table 1.

Categories of the $\mathrm{CMOHK}$ were regressed over the variables recorded in the study through a multivariate

\begin{tabular}{|c|c|c|c|}
\hline Parameters & $n(\%)$ & СMOHK score & $P$ \\
\hline \multicolumn{4}{|l|}{ Gender } \\
\hline Male & $24(10)$ & $12.8 \pm 2.8$ & 0.004 \\
\hline Female & $216(90)$ & $15.3 \pm 1.9$ & \\
\hline \multicolumn{4}{|l|}{ Age } \\
\hline$<35$ & $81(33.7)$ & $14.5 \pm 2.1$ & $<0.001$ \\
\hline $35-44$ & $84(35)$ & $14.3 \pm 1.3$ & \\
\hline$>44$ & $75(31.3)$ & $10.9 \pm 0.3$ & \\
\hline \multicolumn{4}{|c|}{ Geographical location } \\
\hline Urban & $114(47.5)$ & $14.2 \pm 1.3$ & 0.92 \\
\hline Rural & $126(52.5)$ & $13.9 \pm 1.9$ & \\
\hline \multicolumn{4}{|c|}{ Medium of instructions } \\
\hline English & $21(9)$ & $14.8 \pm 1.8$ & 0.99 \\
\hline Kannada & $219(91)$ & $14.1 \pm 1.6$ & \\
\hline \multicolumn{4}{|l|}{ Type of schools } \\
\hline Private & $21(9)$ & $14.1 \pm 1.8$ & 0.99 \\
\hline Government & $219(91)$ & $14.8 \pm 1.6$ & \\
\hline \multicolumn{4}{|c|}{ Type of school teachers } \\
\hline Primary & $111(46.3)$ & $14.4 \pm 1.4$ & 0.004 \\
\hline High & $129(53.7)$ & $11.2 \pm 1.2$ & \\
\hline \multicolumn{4}{|l|}{ Education } \\
\hline Diploma & $108(45)$ & $13.8 \pm 1.3$ & 0.03 \\
\hline Graduation & $132(55)$ & $15.3 \pm 1.9$ & \\
\hline \multicolumn{4}{|l|}{ Income } \\
\hline$<10 \mathrm{~K}$ & $55(23)$ & $13.8 \pm 1.3$ & 0.002 \\
\hline $10-20 \mathrm{~K}$ & $81(33.7)$ & $14.3 \pm 1.6$ & \\
\hline$>20 \mathrm{~K}$ & $104(43.3)$ & $15.2 \pm 1.8$ & \\
\hline
\end{tabular}

regression analysis. Eliminating for probable confounders, statistically significant difference was observed for gender with an odds ratio (3.6 [0.6-21.8]) compared to the females. A statistically significant inverse relation was observed with regard to age of studied participants with an odds ratio (5.7 [2.4-13.6]) in fair/poor category compared to their lesser age counterparts as shown in Table 2.

Primary school teachers exhibited a consistently better CMOHK scores, 0.003 (0.001-0.011) compared to their high school counterparts, 0.003 (0.001-0.012). There was an inverse association between educational levels in relation to $\mathrm{CMOHK}$ scores, with odds of $0.28(0.06-0.08)$ and $0.36(0.21-0.92)$, respectively.

Analysis of the CMOHK scores in relation to oral health status revealed a statistically significant inverse relation for gingival bleeding $(13.9 \pm 1.1$ vs. $15.3 \pm 1.3)$ and periodontal pockets $(13.9 \pm 1.9$ vs. $16.5 \pm 1.6)$, but no difference was observed for dental caries experience of the participants as shown in Table 3. Further analysis of CMOHK scores and decayed 
Jagan et al.: Conceptual knowledge of oral health

\begin{tabular}{|c|c|c|c|c|c|}
\hline \multirow[t]{3}{*}{ Variables } & \multicolumn{5}{|c|}{ CMOHK scores } \\
\hline & \multirow{2}{*}{$\begin{array}{c}\text { Good } \\
n\end{array}$} & \multicolumn{2}{|r|}{ Fair } & \multicolumn{2}{|r|}{ Poor } \\
\hline & & $n$ & Beta (OR $[95 \% \mathrm{CI}]$ ) & $n$ & Beta (OR [95\% Cl]) \\
\hline \multicolumn{6}{|l|}{ Gender } \\
\hline Female & 94 & 75 & Reference Group & 47 & $\mathrm{R}$ \\
\hline Male & 12 & 6 & $0.88(2.4[0.4-13.8])$ & 6 & $1.2(3.6[0.6-21.8])$ \\
\hline \multicolumn{6}{|l|}{ Age } \\
\hline$>44$ & 47 & 18 & Reference Group & 10 & $\mathrm{R}$ \\
\hline $35-44$ & 34 & 38 & $1.21(3.3[1.6-7.02])^{\star}$ & 12 & $0.54(1.7[0.6-4.5])$ \\
\hline$<35$ & 25 & 25 & $0.94(2.5[1.1-5.6])^{*}$ & 31 & $1.74(5.7[2.4-13.6])^{*}$ \\
\hline \multicolumn{6}{|c|}{ Geographical location } \\
\hline Rural & 61 & 38 & Reference Group & 27 & $\mathrm{R}$ \\
\hline Urban & 45 & 43 & $0.59(1.8[0.9-3.3])$ & 26 & $0.16(1.17[0.5-2.3])$ \\
\hline \multicolumn{6}{|c|}{ Medium of Instructions } \\
\hline Vernacular & 98 & 74 & Reference Group & 47 & $\mathrm{R}$ \\
\hline English & 8 & 7 & $-0.09(0.9[0.3-2.6])$ & 6 & $-0.16(0.84[0.2-2.7])$ \\
\hline \multicolumn{6}{|c|}{ School management } \\
\hline Public & 98 & 74 & Reference Group & 47 & $\mathrm{R}$ \\
\hline Private & 8 & 7 & $-0.147(0.86[0.2-2.4])$ & 6 & $-0.44(0.63[0.2-1.9])$ \\
\hline \multicolumn{6}{|l|}{ Type of schools } \\
\hline High schools & 5 & 75 & Reference Group & 49 & $\mathrm{R}$ \\
\hline Primary schools & 101 & 6 & $-5.84(0.003[0.001-0.011])^{*}$ & 4 & $-5.95(0.003[0.001-0.012])^{*}$ \\
\hline \multicolumn{6}{|l|}{ Education } \\
\hline Graduate & 55 & 36 & Reference Group & 17 & $\mathrm{R}$ \\
\hline Diploma & 36 & 45 & $-1.07(0.34[0.09-1.1])$ & 51 & $-1.5(0.20[0.05-0.75])^{*}$ \\
\hline
\end{tabular}

\begin{tabular}{|c|c|c|c|}
\hline Parameters & $n(\%)$ & CMOHK scores & $P$ \\
\hline \multicolumn{4}{|l|}{ DMFT } \\
\hline Very low & $94(40)$ & $14.0 \pm 1.4$ & 0.09 \\
\hline Low & $58(25.5)$ & $14.04 \pm 1.1$ & \\
\hline Moderate & $72(30)$ & $14.0 \pm 2.1$ & \\
\hline High & $16(6.6)$ & $14.16 \pm 1.6$ & \\
\hline \multicolumn{4}{|c|}{ Gingival bleeding } \\
\hline Present & $166(69.2)$ & $13.9 \pm 1.1$ & 0.0001 \\
\hline Absent & $74(31.1)$ & $15.3 \pm 1.3$ & \\
\hline \multicolumn{4}{|c|}{ Periodontal pockets } \\
\hline Present & $60(24.1)$ & $13.9 \pm 1.9$ & 0.0001 \\
\hline Absent & $180(75.8)$ & $16.5 \pm 1.6$ & \\
\hline
\end{tabular}

DMFT: Decayed-missing-filled teeth, CMOHK: Comprehensive Measure of Oral Health Knowledge

component alone revealed a highly significant inverse relation as shown in Table 4.

\section{DISCUSSION}

This study was undertaken to assess the levels of conceptual knowledge and its relation to oral health status among school teachers in Sullia Taluk, Dakshina Kannada. Studies have traditionally focused on oral health literacy among the patients and selected group of professionals. In this study, we have focused on conceptual knowledge among school teachers who can undoubtedly talk and pronounce in a more effective way than others.

Further, teachers constitute an important, influential part of the society and play an important role in the formation and modification of behaviors of young children. Therefore, oral health knowledge is critically important to them not only for their own oral health but also for the children that they are interacting with and teaching. ${ }^{[8]}$

This study is first to explore the relationship between conceptual knowledge and oral health outcomes in a population-based sample of school teachers in India. Hence, interpretation of the findings of this study should be made with caution.

The process of developing a questionnaire involved four main topic areas: basic knowledge of oral health, caries prevention and management, periodontal disease and management, and oral cancer and management. Originally, the questionnaire was 44 items. Later on, it was modified for a 23-item questionnaire. ${ }^{[8]}$ The modified CMOHK questionnaire with 23 questions was adopted in 


$\begin{aligned} & \text { Table 4: Comprehensive Measure of Oral Health } \\
& \text { Knowledge and decayed component of dental caries } \\
& \text { experience }\end{aligned}$
\begin{tabular}{lccc}
\hline Decayed component & $\boldsymbol{n}(\%)$ & CMOHK score & $\boldsymbol{P}$ \\
\hline Very low & $80(34)$ & $14 \pm 2.4$ & $<0.001$ \\
Low & $79(33)$ & $11 \pm 3.4$ & \\
Moderate & $67(28)$ & $12 \pm 1.3$ & \\
High & $14(6)$ & $9 \pm 1.2$ & \\
\hline CMOHK: Comprehensive Measure of Oral Health Knowledge
\end{tabular}

our study; further, the questionnaire was pretested and a few necessary modifications were performed, both the English and the regional language versions were distributed to the participants, and the participants were free to answer whichever they were comfortable with.

A study conducted by Macek et al., which compared three oral health literacy instruments, showed that the CMOHK scores showed more variability in assessing patients oral health compared to REAL-M and TOFHLA. ${ }^{[6]}$

The mean CMOHK score of this group was $12.5 \pm 1.3$ and is considered to be fair. Comparable inferences were obtained in the previous studies conducted by Parker et al. and Lee et al. on other populations with different health literacy instruments. ${ }^{[9,10]}$

This study revealed that an increase in age was associated with low level of conceptual knowledge in accordance with which is found similar to the studies conducted by McQuistan et al. and Reshmi Haridas et al. but in contrast with the findings of the study conducted by Jones et al. for health literacy. ${ }^{[11-13]}$

Conceptual knowledge scores of male participants in the present study were lower compared to the female participants; a similar trend has been reported in the findings of study conducted by Gambhir et al. ${ }^{[14]}$ Higher income and better education were associated with higher levels of $\mathrm{CMOHK}$ scores similar to the findings of the study conducted by McQuistan et al. ${ }^{[12]}$

In this study, we found a statistically significant difference for CMOHK scores among primary and high school teachers where primary school teachers had a better conceptual knowledge than there senior counterparts. Probable reason for this finding could be the type of curriculum that is provided to the students at that level of teaching for high school teachers, whereas primary school teachers are being constantly trained and retained in the educational system, thus having a better conceptual knowledge and oral health status.

Further, it was observed in this study that conceptual knowledge and oral health status were significantly associated in an inverse relation in accordance with the studies conducted by Wehmeyer et al., Ueno et al., and Lee et al.; however, it is emphasized that these studies have focused on oral health literacy and not conceptual knowledge. ${ }^{[3,5,9]}$

One may argue that the sample studied in our study is a region-specific one; however, we would like to stress that the basic sociodemographic factors of school teachers across India remains the same (qualification, income, gender, etc. $){ }^{[6]}$ It is prudent to realize that this study is the first of its kind to test these relationships in India. The findings of this study suggest that age, gender, income, education, type of schools, and poor oral health status are associated with conceptual knowledge, and conceptual knowledge is positively linked with improved oral health.

Schools being the first level of learning may be regarded as the most essential aspect in an individual's life. The schools are an effective forum to enhance general as well as the oral health awareness among children. ${ }^{[8]}$ Students follow what teachers do and say. Teachers are considered as role models to transmit values of life. School teachers by virtue of their training can influence a large number of children, thereby playing a major role in shaping of oral health practices and behavior and also in decision-making for oral health care ${ }^{[16]}$ It is therefore important that their own oral health knowledge is good and their oral health behavior conforms to expectation of the population. ${ }^{[16]}$

\section{CONCLUSION}

We conclude that conceptual knowledge is a critically important aspect of oral health and is influenced by gender, age, education, and income.

We recommend that conceptual knowledge and issues such as tobacco consumption, oral health self-care, and utilization of dental services can be studied. The effect of conceptual knowledge on parents/caregivers/ healthcare providers and their associated subgroups may be an interesting avenue of further research.

\section{Financial support and sponsorship}

Nil. 


\section{Conflicts of interest}

\section{There are no conflicts of interest.}

\section{REFERENCES}

1. Sørensen K, Van den Broucke S, Fullam J, Doyle G, Pelikan J, Slonska Z, et al. Health literacy and public health: A systematic review and integration of defi nitions and models. BMC Public Health 2012;12:80.

2. Pleasant A. Advancing health literacy measurement: A pathway to bettr health and health system performance. J Health Commun 2014;19:1481-96.

3. Wehmeyer MM, Corwin CL, Guthmiller JM, Lee JY. The impact of oral health literacy on periodontal health status. J Public Health Dent 2014;74:80-7.

4. People H. Available from: http://www.Healthypeople.Gov/Document/ HTML/Volume2/16MICH.Htm2010. [Last accessed on 2015 Nov 03].

5. Ueno M, Takeuchi S, Oshiro A, Kawaguchi Y. Relationship between oral health literacy and oral health behaviors and clinical status in Japanese adults. J Dent Sci 2013;8:170-6.

6. Macek MD, Haynes D, Wells W, Bauer-Leffler S, Cotten PA, Parker RM, et al. Measuring conceptual health knowledge in the context of oral health literacy: Preliminary results. J Public Health Dent 2010;70:197-204.

7. World Health Organization. Oral Health Surveys: Basic Methods. France: World Health Organization. 2013. Available from: http://www. apps.who.int/iris/bitstream/10665/97035/1/9789241548649_eng.pdf. [Last accessed on 2015 Nov 03].
8. Ahmad MS. Oral health knowledge and attitude among primary school teachers of Madinah, Saudi Arabia. J Contemp Dent Pract 2015;16:275-9.

9. Lee JY, Divaris K, Baker AD, Rozier RG, Vann WF Jr. The relationship of oral health literacy and self-effi cacy with oral health status and dental neglect. Am J Public Health 2012;102:923-9.

10. Parker EJ, Jamieson LM. Associations between indigenous Australian oral health literacy and self-reported oral health outcomes. BMC Oral Health 2010;10:3.

11. Jones M, Lee JY, Rozier RG. Oral health literacy among adult patients seeking dental care. J Am Dent Assoc 2007;138:1199-208.

12. McQuistan MR, Qasim A, Shao C, Straub-Morarend CL, Macek MD. Oral health knowledge among elderly patients. J Am Dent Assoc 2015;146:17-26.

13. Reshmi Haridas SS, Ajagannanavar SL, Tikare S, Maliyil MJ Kalappa AA, et al. Oral health literacy and oral health status among adults attending dental college hospital in India. J Int Oral Health 2014;6:61-6.

14. Ramandeep G, Arshdeep S, Vinod K, Parampreet P. Oral health literacy among clients visiting a Rural Dental College in North India-A cross-sectional study. Ethiop J Health Sci 2014;24:261-8.

15. Ramachandran V, Pal M, Jain S, Shekar S, Sharma J. Teacher motivation in India. Discussion Paper, 2005. Bangalore: Azim Premji Foundation;2005.

16. Sekhar V, Sivsankar P, Easwaran M, Subitha L, Bharath N, Rajeswary K, et al. Knowledge, attitude and practice of school teachers towards oral health in Pondicherry. J Clin Diagn Res 2014;8:12. 